\title{
The Case Of Merit Pay In A Public University Setting
}

Jacob Joseph, (E-mail: ffjj@uaf.edu), University of Alaska, Fairbanks

Steven P. Landry, (E-mail: ffspl@uaf.edu), University of Alaska, Fairbanks

Kwangseek Choe, (E-mail: ffkc1@uaf.edu), University of Alaska, Fairbanks

Rashmi Prasad, (E-mail: afrp2@cbpp.uaa.alaska.edu), University of Alaska, Anchorage

\begin{abstract}
This case examines the issue of merit-based pay as an incentive mechanism within a state university context. Students in a business school setting are asked to apply organizational behavior and human resource theory to a non-business setting. This case evolved from a real setting involving the usual suspects (faculty) in a business school. The actual situational process was contentious. It is noteworthy, that as academics who teach in a business institution, we often prove better at imparting the mechanics and technical aspects of theory than the application end of business. Faculty and business school institutions may find interest in this study with respect to student perspectives on the issue of merit pay in general and within a university context specifically. Students may find this case intriguing because of their connection to a university and how an exercise of this nature may take place within the backdrop of the environment with which they think they are familiar. Prospective users of the case may wish to discuss the different applicable areas of human resource management although the main thrust is in the area of compensation and the direct application of merit pay. Related issues for possible inclusion consist of job analysis, job descriptions, job specifications, performance appraisals, criterion contamination, and criterion deficiency. Side issues include minority status considerations and the concepts of procedural justice (was the process for determining merit pay fair?) and distributive justice (was the final, end result of merit pay equitable?).
\end{abstract}

\section{INTRODUCTION}

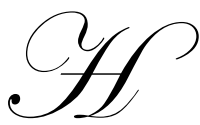

orse-feathers! Nobody will buy into this merit baloney," bellowed Hank Wilson, the Dean of the College of Engineering at the University of Alaska. ${ }^{1}$ He was hot under the collar and the room was abuzz with comments flowing back and forth. In the midst of this "hornet's nest", Ken Cato, Dean of the College of Business, reflected on the events that preceded the current conflagration.

It was a cool, spring morning in Cicely, Alaska as Dean Ken Cato headed to the Provost Council meeting with the Provost John Kelso and all the other deans of the various academic programs. Ken Cato, recently elected as Dean of the College of Business by his colleagues anxiously hoped to impress the provost and confirm the faith of his fellow business faculty. Thoughts and ideas of improvement swirled in his head as he walked into Provost Kelso's office. Dean Cato, an Economics professor had been elected from among the faculty four months previously. The College of Business represents one of six colleges at the University of Alaska, comprising $15 \%$ of the student body in terms of enrollment numbers. In addition, the College contributes to the overall mission of the university by providing scholastic research, acquiring funded research grants, and disseminating undergraduate, graduate and industry based instruction.

The meeting started with all the customary introductory greetings and exchange of pleasantries followed by the various items on the agenda. As the meeting reached its mid-point, Provost Kelso came to the main issue he wished to discuss with the council.

\footnotetext{
${ }^{1}$ Names of individuals and organizations have been changed
} 


\section{THE PROPOSAL}

Kelso: "I have a proposal for the academic faculty at the university and want faculty input along with your guidance. I am proposing the university replace the automatic annual salary raise scheme with a merit pay plan. In this plan, the budgeted merit pay will total $8 \%$ of payroll expenses and you as the academic heads of your respective units will have to decide how to dole out the rewards but under no circumstances will the plan allow for equal raises. Rewards should reflect distribution in an equitable manner."

As the Provost finished speaking all hell broke loose and pandemonium ensued. The various deans and directors squabbled as detractors of the plan traded arguments back and forth with proponents of the plan regarding its efficacy or the lack thereof. Several arguments centered round the metrics of performance to be used for productivity. Richard Potter, the dean of the College of Sciences, wanted productivity, and hence merit, based on grants and publications, while Cynthia Stern, the dean of the Liberal Arts College, wanted productivity to be based on the number of classes taught. Dean Cato was somewhat indifferent to either proposal as he figured that his College of Business would range slightly better than average with either measure of productivity. Other deans pushed their programmatic strengths, such as number of graduating doctoral students, student credit hours generated, value to the community, grant dollars generated and so on.

While the discourse at the Provost Council was progressing, mixed feelings were going through Dean Cato's mind. He thought to himself, "Merit pay, a great idea but here I am as the new dean having to deal with this additional ball, along with all the other administrative balls that I have to juggle." As the other academic directors and deans, headed out the room at the conclusion of the meeting room, the provost instinctively cried out.....

Kelso: "Remember, equity, not equality!"

\section{Administrative meeting at the College of Business}

Back at the College of Business, Dean Cato called his three department heads together to discuss his predicament. The three departments in the college consisted of accounting \& finance, management \& marketing, and economics.

Cato: "There you have it folks. That's the whole story of what happened at the meeting today. So how do we proceed from here?"

As the faculty whispered among themselves, Cato could infer that the news hit the faculty like an Alaskan avalanche. The faculty pensively reflected on questions such as, how to define merit, how to administer the plan, and how it would affect their salaries.

Dean Cato, sensing their anxiety, spoke up:

Cato: "First thing we need is to form a committee."

One would have expected that the selection of committee members to be an easy task. Noting the threedepartment make-up of the college and a need for a fair and meaningful representation of faculty input in the merit decision, Dean Cato decided to step to the plate and set the ground rules for the selection process. For the sake and appearance of fairness, or procedural justice, he decided to form a committee of 6 members ( 2 persons including the head from each department) who would determine the allocation of bonuses. While there were 4 dissenters regarding the committee structure proposal, generally the rest of the faculty agreed with the dean's suggestion. Those who disagreed stated a couple of reasons. One of the dissenters felt that department size should determine the selection of committee members, based analogously to the U.S. House of Representatives. These dissenters disagreed with the equal representation format from each department, which more reflected the composition of the U.S. Senate. Another disagreement centered around the use of department heads in the decision-making process. 
The department heads were viewed as having questionable allegiances since they were seen as quasi-administrators and hence not totally reflective of faculty viewpoints.

From the outset several administrative problems associated with the operationalization of this "merit" exercise arose. Some of these issues included:

\section{Issues}

- $\quad$ how to measure "merit"

- what time period to use for the merit period

- $\quad$ whom to include as eligible for merit awards

- $\quad$ how to dole out the merit

$\circ \quad$ percentage of base pay as merit across the categories of performers

- absolute dollars of merit regardless of discipline/department

- $\quad$ how to make tradeoffs for different teaching loads (teaching 4 vs. 5 classes per academic year)

Beyond these issues, there lay the ultimate political lightening rod on everyone's mind:

"How can I be evaluated fairly when scholarly research is compared across the 3 departments and 5 disciplines?"

\section{BACKGROUND INFORMATION ON ACADEMICS}

As background for the uninitiated, the unique or rather distinctive characteristic features of academia lay in its tripartite responsibilities. Faculty members generally perform some combination of teaching, research, and service responsibilities as part of their duties. Of the three duties, perhaps service tends to receive short shrift because of its seeming lack of measurable value to a department. While service is "deemed important", it is merely given lip service (no pun intended). This results since tenure and promotion are rarely bestowed upon an individual for solely excelling in the service area. Depending on the institution, and across organizations within a given institution, teaching and research can vary in importance, but faculty generally have expectations placed on them to excel in both areas. Faculty tend to place greater emphasis on teaching if institutions weight their workload more heavily towards such an endeavor. Importance and emphasis on research largely depends on the function of an institution's reputation in that area. However, notwithstanding any institution-driven priorities or emphases, faculty who wish for greater career mobility will not neglect research. Rather, they will put additional effort in this area to ensure that they do not languish at a career plateau. Generally, faculty at highly reputable institutions are renowned much more for their research, less so for their teaching, and least of all for service. This does not mean that faculty do not perform well across all three tripartite duties. In fact, more often than not, good researchers tend to excel at teaching since they can inform their teaching by including their research knowledge in their teaching assignments. It does not necessarily follow, however, that good teachers excel at research.

\section{POSSIBLE DIMENSIONS/CRITERIA OF EVALUATION}

\section{Research Productivity}

Top-Tier Journals

This categorization reflects the top journal publications in specific disciplines. This criterion by its very title and nature may prove contentious. This is particularly true when trying to define and list the appropriate "top" journals. In the various disciplines, published articles exist that reflect journal rankings and/or classifications categorizing the journals into various tiers/levels. While these rankings might not garner fully agreed upon consensus, adjustments can be made through faculty involvement to come up with their own rankings. 


\section{Refereed Journals}

This category opens up a wide spectrum of choices from high-end to low-end journals in terms of perceived "quality". Refereeing can occur through a double-blind or single-blind editorial review process. Refereeing assumes a certain degree of unbiased, objective review by an expert in the field. Quality concerns can arise depending on the rigor of the review process for a given journal.

Non-Refereed Journals

This category may also create controversy because there are journals held in high esteem that may invite and publish some manuscripts not necessarily subjected to an objective, unbiased review process. Usually, nonrefereed publications could include editorially reviewed articles and what the Association to Advance Collegiate Schools of Business (accrediting body known commonly by the acronym AACSB) refers to as other "publicly disseminated information."

\section{Conference Presentations}

Conferences serve an important venue and purpose for the dissemination of knowledge. However, even if published in proceedings of the conferences, presentations of papers hold less clout with regard to research value vis-à-vis refereed publications. The reason for this may be that conference presentations are not meant to be the final product, but a stepping-stone for refinement and polished into a manuscript publication. Also, in general and in line with stepping stone logic, conferences use less rigor than journals in determining acceptances.

\section{Teaching Productivity}

\section{Teaching Loads}

Research oriented schools require lighter teaching loads than institutions with a primary emphasis on teaching. However, regarding the latter, faculty who produce research may receive relatively lighter teaching loads than those who do not publish. The uninitiated student may find interest in realizing that teaching loads for faculty can vary anywhere from 3 to 8 course sections per year. This will depend on the mission and orientation of the institution or program. Teaching loads can also be moderated by taking into consideration the number of different course preparations (preps) that a faculty member can expect. Accounting for all the possible variables involved in the teaching dimension would become extremely onerous.

\section{Teaching Evaluations}

As with research criteria, this teaching dimension is fraught with controversy. Teaching evaluations at the University of Alaska are based primarily on teaching evaluations by students of their instructors. While this type of evaluation represents but one possible form of appraisal, it constitutes the prevalent method at this institution. Partially for the sake of expediency, and hoped for objectivity, student evaluations tend to dominate. Peer evaluations appear infrequently, typically related to tenure and promotion decisions. Instructors may feel less inclined to discuss this section lest students perceive a certain advantage in this information if indeed student evaluations carry significant weight in administrative decision making thus affecting faculty.

\section{Class Sizes}

This area of teaching arguably affects productivity from a couple of perspectives. From the institution's perspective an instructor with more students provides "economic value" to the institution by "spreading out" the cost of salary over a large number of students. In extreme cases, institutions must cancel classes without a sufficient number of students, thus having to "eat" the cost of that faculty member. Respectively, with respect to these two situations, from the instructor's perspective, the large class size can negatively affect the instructor's teaching evaluations because of inability to provide individual attention. Also, large class sizes increase teaching work, thus 
reducing time for research activity. Of course, instructors with small class sizes or cancelled sections benefit from the opposite of these effects.

\section{Graduate/Undergraduate}

This categorization reflects graduate versus undergraduate classes. More weight is attached to teaching graduate courses given the rationale that graduate courses require a greater level of rigor, requirements, and preparation in delivering the course. At some universities teaching at the graduate level is a privilege reserved for the research productive faculty.

One can argue that teaching an undergraduate class with over 100 students definitely possess its share of challenge and demands. Thus there may be a trade-off for undergraduate size versus graduate-level standing.

\section{Service Productivity}

Service typically within an academic setting means an internal (to the institution) activity.

\section{University Service}

University-wide service generally lies at the high end in university settings. The level of time commitment required often can be quite intense in this area. Also, selection to these university committees may be highly discriminating. Example of this type of service include becoming a member of the Human Subjects or Institutional Research Review Board, or the Faculty Senate.

\section{College Service}

College or school-wide service usually revolves around the general disciplines of a college or school. This type of service tends to mirror university-wide service although limited to a smaller, localized settings. A common type of service at this level may be the Promotion and Tenure Committee or service on the AACSB Accreditation Committee.

\section{Department Service}

This is specialized service that incorporates some of the duties mentioned in the previous two areas of service (university and college/school) but with a specialized, discipline-oriented focus. A typical example in this area would be the role of department chair/head.

\section{Professional Service}

This dimension measures a wide spectrum of service. It may include such factors as academic organizations, professional, practitioner oriented associations, and clubs. It can vary from donated time services rendered as a basis of expertise to nonprofit organizations to lectures conducted in a public setting for nominal honorarium. This service carries with it a presumption that a person thus involved is in fact honing their skill sets and putting into practice their expertise in inter-organizational settings.

\section{Overall Productivity Determination}

Having considered all the above issues and the various aspects of the tripartite duties of faculty Dean Cato considered what he might do to initiate the process and how he might inform and advise the committee charged with providing merit-based incentive proposals. 
How might the committee consider assigning weights in the tripartite areas and weights within the three areas of responsibilities (research, teaching, and service)? Depending on the varied mission of the college, the weights might have to posses some flexibility.

\section{Discussion Questions}

Q1. How would you as one of the committee members make the decision/series of decisions in allocating the merit raises? In other words, how would you measure merit?

Q2. What time period do you use for merit awards?

Q3. Whom do you include to be eligible for merit pay awards?

Q4. How do you dole out the merit pay?

- Percentage of base pay as merit, across the categories of performers?

- Absolute dollars of merit regardless of discipline/department?

Q5. How do you make tradeoffs for different teaching loads (teaching 4 vs. 5 classes)?

\section{Additional questions}

Q6. How can a person be evaluated fairly when scholarly research is compared across the 3 departments and 5 disciplines (Accounting \& Finance, Economics Marketing \& Management)?

Q7. What are some potentially "explosive" issues in the merit exercise?

Q8. Suggest measures or mechanisms to diffuse the "political" problems.

Q9. Consider the transparency of the committee's workings. Should procedures be openly communicated? Should deliberations be open?

Listed below is the information needed by the committee to make the decisions. The 3 departments are made up of the following faculty along with corresponding data that the committee had at their disposal.

$\underline{\text { Accounting \& Finance }}$

Walter House

Samir Hamdan

Loretta Matthews

Patrick Kendrick

Andy Keith

Sam Chrisman

\section{$\underline{\text { Economics }}$}

George Guthridge

Henry McCarthy

Ben Jamieson

Peter Martinez

Richard Demming

Loren Reiss

George Kessler
Management \& Marketing

Morgan Lowe

Connor Johnson

Brenda Dennison

Perry Dickson

Jerry Jensen

Terry Radford

Steven Benson

\section{THE CASE OF MERIT PAY IN A PUBLIC UNIVERSITY SETTING}

\section{Instructor Notes \\ General Approach}

This case was an actual administrative exercise carried out in a public university for the express purpose of conducting a merit pay exercise. Faculty members were selected by their peers to make a one-time pay administration decision. Many parts of the case such as names, salaries and the process of merit determination have been disguised. The process proved contentious. One finds it noteworthy that as academics who teach in business schools, we are often better at imparting the mechanics and technical aspects of theory than execute at the application end of business. Students may find this case interesting because of their connection to a university and how an exercise of this nature may take place. 
User of this case may wish to discuss the different applicable areas of human resource management although the main thrust lies in the area of compensation and the direct application of merit pay. The instructor can start by focusing on the importance of good documentation in conducting performance appraisal. Depending on the type of institution, instructors can point students toward assigning weightings based on their perceived value placed on the tripartite responsibilities of faculty. It is all too easy for us, as instructors to introduce our biases as we cater to our personal strengths, whether it lies in research, teaching or service. Importantly, one should reflect on the mission of the institution and its main goals. If you find yourself in a research oriented institution, you may want to emphasize research productivity accordingly; and if in a predominantly teaching school, emphasize teaching productivity. Publicly, all universities point to the importance of the tripartite responsibilities. However, these should receive respective emphases in varying degrees according to the mission of the college and the university.

When discussing the case, the instructor may choose to start with job analysis. Discuss the tripartite responsibilities of a college professor. Pull up a recent recruitment notice or job advertisement for a tenure track faculty position for your institution. You may want to review with your students, the differences between a job description and a job specification. Discuss the aspects of a performance appraisal and in particular discuss criterion contamination (Are the criteria used to measure overall productivity relevant for rewarding employees with merit pay inappropriate?), and criterion deficiency (do the criteria sufficiently and adequately measure productivity or do better measures of productivity exist?). Are these concepts relevant to this case study?

As a side issue, when distributing merit pay, it may be interesting to look at the final distribution to see if there is an adverse impact affecting women and minorities. While the faculty members in this case have not been identified by gender, it is fairly simple to infer through the names given. The minority status may be harder to distinguish with regard to race and color, but national origin may be easier to determine especially with the "foreign" sounding names.

Finally, since this exercise deals with merit and the concept of equity and fairness, discussion of the concepts of procedural justice (was the process for determining merit pay fair?) and distributive justice (was the final result of how merit pay was doled out equitable?) might prove beneficial.

In the following sections, the dimensions have been loosely defined for instructors to clarify to their student audiences. Most students' familiarity with the criteria mentioned in this case may vary or even may approximate close to nil. These descriptions may not be readily accepted, so instructors should feel free to modify them appropriately.

\section{One Possible Approach}

Research and teaching might receive approximately equal weightings of $40 \%$ since this institution stresses research and teaching with equal importance. Research-oriented faculty have lighter teaching ( 3 or 4 classes) loads. At the same time those who choose a teaching track, thus making a tradeoff with research, can expect a higher teaching load (5 or 6 classes). Both categories of faculty are considered equally productive and valued members of the institution.

Within the research area, the following weighting breakdown might arise: "top tier" publications $(60 \%)$, refereed but less than top shelf quality (25\%), non-refereed publication (10\%), and conference proceedings (5\%).

With the teaching component, this weighting breakdown could surface: student evaluation of instructors at $90 \%$ since this is the only method usually available albeit a controversial measure; number of classes taught receives a weighting of 5\%; while the number of Graduate classes taught would receive a 5\% weighting.

Service is allocated a $20 \%$ value of the tripartite duties. The service component comprises university-wide, college-wide, and external or professional service and as such gets allocated $40 \%, 40 \%$ and $20 \%$ weightings, respectively. 


\section{Response Guide to Primary Questions}

\section{Q1. How would you as one of the committee members make the decision/series of decisions in allocating} the merit raises? In other words, how would you measure merit?

Usually within a "typical college", the department head, or dean or a committee of faculty or a combination of all three makes decisions in allocating merit pay. In the case of this particularly situation at the University of Alaska, a committee provided some proposals regarding merit ranking and the dean then decided the merit pay in a two step process.

In this case merit was measured through a composite of standardized scores for research, teaching and service. This should have been stated prior to the merit pay implementation. In a "true" merit pay allocation, participants are informed of the metrics of performance prior to utilization of the plan. In the real, original situation, the exercise was flawed since faculty should have been informed of the merit pay exercise before the fact. Further, each college should determine its own set of criteria and measures of productivity.

\section{Q2. What time period do you use for merit award?}

Merit is usually measured over a time period of one year but in this case it was evaluated over a 2 year period and the values provided were average values. Should an organization consider longer time periods? For instance, what about using a five-year "moving average"? Instructors and classes can generate significant discussion regarding this issue.

\section{Q3. Whom do you include to be eligible for merit pay awards?}

Eligibility for merit pay was usually restricted to full-time tenure track and tenured faculty. In this case it was limited to those who were working for the two previous consecutive years 2001 and 2002. Adjunct and visiting faculty typically worked subject to explicit term (time bounded) contracts not usually amenable.

\section{Q4. How do you dole out the merit?}

- $\quad$ Percentage of base pay as merit across the categories of performers?

- Absolute dollars of merit regardless of discipline/department?

A question of concern may arise as whether to disburse the merit on a percentage basis or on an absolute dollar basis. There may surface very strong feelings supporting either course of action. Calculations reflecting both bases are provided to examine the respective impact. To reward on an absolute basis would imply that the organization does not discriminate according to individuals' discipline, but rather treats those in each tier of performance equally for all within that category. However, those in the higher compensated disciplines like accounting would argue for merit to be based on a percentage basis. It would be interesting to get various opinions from students as to their perception of which would be a more equitable way to dispense merit. Review to Table 2 to see the differences in the sample approaches provided.

\section{Q5. How do you make tradeoffs for different teaching loads (teaching 4 vs. 5 classes)}

As stated earlier, those who are research productive received a 3 or 4 class per year teaching load while those determined less research productive were assigned a 5 class teaching load. The rationale for this rested on the premise of time commitment. Specifically, faculty conducting and producing scholarly output (research) require time for that activity. Faculty not so engaged should devote an analogous amount of time and effort toward an increased teaching load. 


\section{Response Guide for Additional Questions}

Beyond these issues, lay the political tinderbox issues that could, and probably would, surface.

Q6. How can a person be evaluated fairly when scholarly research is compared across the three departments and 5 disciplines (Accounting \& Finance, Economics, and Marketing \& Management)

Usually major journals in the functional areas of business have published articles providing rankings for journals in the respective discipline. The College or its committee should attempt to reach consensus as to the top tier journals by faculty in their respective disciplines or departments. Various scholarly business programs across the country have rankings that they use for tenure and promotional purposes. Between the journal rankings and business program rankings of journals, a list of top-tiered rankings can be derived.

As for classification of what constitutes peer reviewed or refereed journals, Cabell's publication distinguishes between refereed and editorially reviewed journals. In addition most journals that elicit manuscripts also state the type of review to which manuscripts are subjected.

\section{Q7. What are some of the potentially "explosive" issues in the merit exercise?}

In a smaller college setting where departments are combined as depicted here with Finance and Accounting and likewise with Marketing and Management, there is a natural tendency to allow discipline-based biases to enter into the evaluation (notwithstanding faculty's supposed training to be objective and fair).

One view holds that committee members should include only tenured faculty since the rankings by their very nature will result in some "winners" and some "losers". Feelings will be hurt and egos bruised. So as not to have any retribution against untenured faculty, who are vulnerable, the College should exclude them from the decision making process. Even with tenured faculty selected for the committee, it would be wise for each person to turn in their individual rankings, anonymously to the dean. Then the dean should handle/calculate the composite rankings to avoid personal attribution.

\section{Q8. Suggest measures or mechanisms to diffuse the "political" problems}

Every institution has its own set of unique political issues. As stated previously in the response to Q7, one of those solutions can be to exclude untenured faculty from serving on the merit pay committee. Having stated that, there were representatives on the actual committee ranging from assistant to associate to full professors. Perhaps, having equal representation from all three departments, as in this case, would provide a measure of fairness.

\section{Q9. Consider the transparency of the committee's workings. Should procedures be openly communicated? Should deliberations be open?}

The committee should decide through consensus, or as close to a consensus as possible or feasible, a formula or means of establishing an equitable method of merit allocation. No "right" answer exists per se, but the research literature notes that procedural justice matters more than distributive justice in the eyes of the evaluated. Prevailing thought suggests that if the process is fair from the start, then the end result would be acceptable to those involved. Transparency is generally a good policy to institute. Many of the problems surrounding compensation related matters have their origin in trust issues or the lack thereof. Thus, the process should be explained to the faculty. Deliberations, on the other hand, should remain within the committee. This should allow for a freer exchange of ideas. The committee could then decide how to best inform its constituents. For example, the committee members could report back to their respective departments, with those department meetings providing feedback. 
Table 1

\begin{tabular}{|c|c|c|c|c|c|c|c|c|c|c|c|c|c|c|c|c|}
\hline & & \multicolumn{6}{|c|}{ Research Productivity } & \multicolumn{3}{|c|}{ Teaching Productivity } & \multicolumn{6}{|c|}{ Service Productivity } \\
\hline & Name & Salary & Top & Ref & No-Ref & Conf & Load & Eval & Cl Sz & Grad & UG & Uni & Sch & Dept & Pro & merit \$ \\
\hline 1 & Steven Benson & $\$ 72,500$ & 0 & 2 & 1 & 2 & 4 & 4.25 & 24 & 2 & 2 & 1 & 1 & 2 & 1 & \\
\hline 2 & Sam Chrisman & $\$ 81,000$ & 1 & 0 & 1 & 1 & 5 & 4.20 & 16 & 0 & 4 & 0 & 2 & 2 & 0 & \\
\hline 3 & Richard Demming & $\$ 65,000$ & 0 & 2 & 3 & 1 & 4 & 3.30 & 20 & 1 & 3 & 1 & 2 & 1 & 1 & \\
\hline 4 & Brenda Dennison & $\$ 79,000$ & 1 & 1 & 0 & 1 & 4 & 4.15 & 24 & 2 & 2 & 0 & 2 & 2 & 1 & \\
\hline 5 & Perry Dickson & $\$ 76,000$ & 0 & 1 & 0 & 1 & 4 & 3.75 & 25 & 2 & 2 & 1 & 1 & 2 & 1 & \\
\hline 6 & George Guthridge & $\$ 68,000$ & 1 & 2 & 0 & 0 & 4 & 4.44 & 14 & 1 & 3 & 1 & 2 & 1 & 0 & \\
\hline 7 & Samir Hamdan & $\$ 80,000$ & 1 & 1 & 0 & 1 & 4 & 3.90 & 10 & 4 & 0 & 1 & 2 & 2 & 0 & \\
\hline 8 & Walter House & $\$ 90,000$ & 0 & 1 & 0 & 1 & 4 & 3.40 & 10 & 2 & 3 & 0 & 2 & 2 & 0 & \\
\hline 9 & Ben Jamieson & $\$ 60,000$ & 1 & 1 & 0 & 1 & 5 & 3.70 & 8 & 2 & 3 & 0 & 2 & 2 & 1 & \\
\hline 10 & Jerry Jensen & $\$ 78,500$ & 1 & 2 & 0 & 1 & 4 & 3.75 & 27 & 1 & 3 & 2 & 2 & 2 & 0 & \\
\hline 11 & Connor Johnson & $\$ 75,500$ & 0 & 2 & 0 & 1 & 4 & 3.45 & 25 & 2 & 2 & 0 & 2 & 2 & 0 & \\
\hline 12 & Andy Keith & $\$ 82,000$ & 0 & 0 & 1 & 0 & 5 & 4.10 & 12 & 1 & 4 & 0 & 2 & 1 & 1 & \\
\hline 13 & Patrick Kendrick & $\$ 86,000$ & 2 & 1 & 0 & 0 & 4 & 3.50 & 12 & 1 & 3 & 1 & 2 & 2 & 0 & \\
\hline 14 & George Kessler & $\$ 65,500$ & 0 & 1 & 2 & 2 & 4 & 4.20 & 30 & 1 & 3 & 1 & 1 & 2 & 1 & \\
\hline 15 & Morgan Lowe & $\$ 82,500$ & 1 & 1 & 1 & 1 & 4 & 4.15 & 25 & 1 & 3 & 0 & 2 & 1 & 2 & \\
\hline 16 & Peter Martinez & $\$ 61,000$ & 1 & 2 & 0 & 0 & 4 & 3.20 & 14 & 1 & 3 & 1 & 2 & 1 & 1 & \\
\hline 17 & Loretta Matthews & $\$ 74,000$ & 0 & 0 & 0 & 1 & 4 & 4.20 & 18 & 0 & 4 & 1 & 2 & 3 & 1 & \\
\hline 18 & Henry McCarthy & $\$ 72,000$ & 1 & 2 & 2 & 1 & 3 & 4.50 & 15 & 1 & 2 & 1 & 2 & 2 & 1 & \\
\hline 19 & Terry Radford & $\$ 79,500$ & 0 & 2 & 1 & 0 & 4 & 3.95 & 17 & 2 & 2 & 0 & 1 & 2 & 0 & \\
\hline 20 & Loren Reiss & $\$ 62,500$ & 0 & 0 & 0 & 1 & 5 & 4.60 & 35 & 1 & 4 & 0 & 2 & 2 & 0 & \\
\hline \multicolumn{17}{|l|}{$\underline{\text { Key }}$} \\
\hline$\overline{\text { Top }}$ & & & & & & & & & & & & & & & & \\
\hline Ref & Refereed journal accep & ut second & d tieres & ournal & & & & & & & & & & & & \\
\hline Non-Ref & \multicolumn{16}{|c|}{ Non-refereed journal acceptance } \\
\hline Conf & \multicolumn{16}{|c|}{ Conference presentation - to include proceedings } \\
\hline Load & \multicolumn{16}{|c|}{ Teaching load (3-5) classes per academic year } \\
\hline Eval & \multirow{2}{*}{\multicolumn{16}{|c|}{ Teaching evaluations based on student opinions of instructor }} \\
\hline Cl Sz & & & & & & & & & & & & & & & & \\
\hline Grad & \multicolumn{16}{|l|}{ Graduate class } \\
\hline UG & \multicolumn{16}{|l|}{ Undergraduate class } \\
\hline Uni & \multicolumn{16}{|l|}{ University service } \\
\hline Sch & \multicolumn{16}{|l|}{ School/College service } \\
\hline Dept & \multicolumn{16}{|l|}{ Departmental service } \\
\hline Pro & \multicolumn{16}{|l|}{ Professional service } \\
\hline
\end{tabular}


Table 2

Research Productivity (40\%)

Teaching Productivity (40\%)

Service Productivity (20\%)

Name

Steven Benson

Sam Chrisman

Richard Demming

Brenda Dennison

Perry Dickson

George Guthridge

Samir Hamdan

Walter House

Ben Jamieson

Jerry Jensen

Connor Johnson

Andy Keith

Patrick Kendrick

George Kessler

Morgan Lowe

Peter Martinez

Loretta Matthews

Henry McCarthy

Terry Radford

Loren Reiss $\begin{array}{llll}0.60 & 0.25 & 0.10 & 0.05\end{array}$

$\begin{array}{lll}0.90 & 0.05 & 0.05\end{array}$

Eval

$\$ 72,500$

$\$ 81,000$

$\$ 65,000$

$\$ 79,000$

$\$ 76,000$

$\$ 88,000$

$\$ 90,000$

$\$ 60,000$

$\$ 78,500$

$\$ 75,500$

$\$ 82,000$

$\$ 86,000$

$\$ 65,500$

$\$ 82,500$

$\$ 61,000$

$\$ 74,000$

$\$ 72,000$

$\$ 62,500$

$\begin{array}{cccc}\text { Top } & \text { Ref } & \text { No-Ref } & \text { Conf } \\ 0 & 2 & 1 & 2\end{array}$

10

3

0

0

0

0

0

0
0

1
0

2

24

$16 \quad 0$

$\begin{array}{llll}0.35 & 0.25 & 0.25 & 0.15\end{array}$

$\begin{array}{ll}2 & \\ 0 & \\ 1 & \end{array}$

(1)

merit \$

Top Top-tiered journal acceptance

Ref $\quad$ Refereed journal acceptance but second \& third tiered journals

Non-Ref Non-refereed journal acceptance

Conf Conference presentation - to include proceedings

Load Teaching load (3-5) classes per academic year

Eval Teaching evaluations based on student opinions of instructor

Cl Sz Class size

Grad Graduate class

UG Undergraduate class

Uni University service

Sch School/College service

Dept Departmental service

Pro Professional service 
Table 3A

\section{Research Productivity}

$\begin{array}{lccccccccc}\text { Name } & \text { Salary } & \text { Top } & \text { zTop } & \text { Ref } & \text { zRef } & \text { No-Ref } & \text { zNon } & \text { Conf } & \text { zCon } \\ \text { Henry McCarthy } & \$ 72,000 & 1 & 0.75 & 2 & 1.039 & 2 & 1.591 & 1 & 0.254 \\ \text { George Guthridge } & \$ 68,000 & 1 & 0.75 & 2 & 1.039 & 0 & -0.68 & 0 & -1.44 \\ \text { Brenda Dennison } & \$ 79,000 & 1 & 0.75 & 1 & -0.26 & 0 & -0.68 & 1 & 0.254 \\ \text { Morgan Lowe } & \$ 82,500 & 1 & 0.75 & 1 & -0.26 & 1 & 0.455 & 1 & 0.254 \\ \text { Jerry Jensen } & \$ 78,500 & 1 & 0.75 & 2 & 1.039 & 0 & -0.68 & 1 & 0.254 \\ \text { Steven Benson } & \$ 72,500 & 0 & -0.92 & 2 & 1.039 & 1 & 0.455 & 2 & 1.949 \\ \text { Samir Hamdan } & \$ 80,000 & 1 & 0.75 & 1 & -0.26 & 0 & -0.68 & 1 & 0.254 \\ \text { Sam Chrisman } & \$ 81,000 & 1 & 0.75 & 0 & -1.56 & 1 & 0.455 & 1 & 0.254 \\ \text { Loren Reiss } & \$ 62,500 & 0 & -0.92 & 0 & -1.56 & 0 & -0.68 & 1 & 0.254 \\ \text { Patrick Kendrick } & \$ 86,000 & 2 & 2.42 & 1 & -0.26 & 0 & -0.68 & 0 & -1.44 \\ \text { George Kessler } & \$ 65,500 & 0 & -0.92 & 1 & -0.26 & 2 & 1.591 & 2 & 1.949 \\ \text { Loretta Matthews } & \$ 74,000 & 0 & -0.92 & 0 & -1.56 & 0 & -0.68 & 1 & 0.254 \\ \text { Ben Jamieson } & \$ 60,000 & 1 & 0.75 & 1 & -0.26 & 0 & -0.68 & 1 & 0.254 \\ \text { Terry Radford } & \$ 79,500 & 0 & -0.92 & 2 & 1.039 & 1 & 0.455 & 0 & -1.44 \\ \text { Andy Keith } & \$ 82,000 & 0 & -0.92 & 0 & -1.56 & 1 & 0.455 & 0 & -1.44 \\ \text { Perry Dickson } & \$ 76,000 & 0 & -0.92 & 1 & -0.26 & 0 & -0.68 & 1 & 0.254 \\ \text { Peter Martinez } & \$ 61,000 & 1 & 0.75 & 2 & 1.039 & 0 & -0.68 & 0 & -1.44 \\ \text { Richard Demming } & \$ 65,000 & 0 & -0.92 & 2 & 1.039 & 3 & 2.727 & 1 & 0.254 \\ \text { Connor Johnson } & \$ 75,500 & 0 & -0.92 & 2 & 1.039 & 0 & -0.68 & 1 & 0.254 \\ \text { Walter House } & \$ 90,000 & 0 & -0.92 & 1 & -0.26 & 0 & -0.68 & 1 & 0.254\end{array}$

\section{$\underline{\text { Key }}$}

Top

zTop

Ref

zRef

Non-Ref

zNon

Conf

zCon
Top-tiered journal acceptance

Standard score (normalized) for top-tiered journal

Refereed journal acceptance but second \& third tiered journals

Standard score (normalized) for refereed journal

Non-refereed journal acceptance

Standard score (normalized) for non-refereed journal acceptance

Conference presentation - to include proceedings

Standard score (normalized) for conference presentation/proceedings 
Table 3B

Teaching Productivity

$\begin{array}{lccccccccc}\text { Name } & \text { Salary } & \text { Load } & \text { Eval } & \text { zEval } & \text { Cl Sz } & \text { zC S } & \text { Grad } & \text { zGrad } & \text { UG } \\ & & & & & & & & & \\ \text { Henry McCarthy } & \$ 72,000 & 3 & 4.50 & 1.37 & 15 & -0.54 & 1 & -0.45 & 2 \\ \text { George Guthridge } & \$ 68,000 & 4 & 4.44 & 1.22 & 14 & -0.68 & 1 & -0.45 & 3 \\ \text { Brenda Dennison } & \$ 79,000 & 4 & 4.15 & 0.51 & 24 & 0.663 & 2 & 0.682 & 2 \\ \text { Morgan Lowe } & \$ 82,500 & 4 & 4.15 & 0.51 & 25 & 0.797 & 1 & -0.45 & 3 \\ \text { Jerry Jensen } & \$ 78,500 & 4 & 3.75 & -0.46 & 27 & 1.064 & 1 & -0.45 & 3 \\ \text { Steven Benson } & \$ 72,500 & 4 & 4.25 & 0.76 & 24 & 0.663 & 2 & 0.682 & 2 \\ \text { Samir Hamdan } & \$ 80,000 & 4 & 3.90 & -0.10 & 10 & -1.21 & 4 & 2.955 & 0 \\ \text { Sam Chrisman } & \$ 81,000 & 5 & 4.20 & 0.63 & 16 & -0.41 & 0 & -1.59 & 4 \\ \text { Loren Reiss } & \$ 62,500 & 5 & 4.60 & 1.61 & 35 & 2.135 & 1 & -0.45 & 4 \\ \text { Patrick Kendrick } & \$ 86,000 & 4 & 3.50 & -1.07 & 12 & -0.94 & 1 & -0.45 & 3 \\ \text { George Kessler } & \$ 65,500 & 4 & 4.20 & 0.63 & 30 & 1.466 & 1 & -0.45 & 3 \\ \text { Loretta Matthews } & \$ 74,000 & 4 & 4.20 & 0.63 & 18 & -0.14 & 0 & -1.59 & 4 \\ \text { Ben Jamieson } & \$ 60,000 & 5 & 3.70 & -0.59 & 8 & -1.48 & 2 & 0.682 & 3 \\ \text { Terry Radford } & \$ 79,500 & 4 & 3.95 & 0.02 & 17 & -0.27 & 2 & 0.682 & 2 \\ \text { Andy Keith } & \$ 82,000 & 5 & 4.10 & 0.39 & 12 & -0.94 & 1 & -0.45 & 4 \\ \text { Perry Dickson } & \$ 76,000 & 4 & 3.75 & -0.46 & 25 & 0.797 & 2 & 0.682 & 2 \\ \text { Peter Martinez } & \$ 61,000 & 4 & 3.20 & -1.80 & 14 & -0.68 & 1 & -0.45 & 3 \\ \text { Richard Demming } & \$ 65,000 & 4 & 3.30 & -1.56 & 20 & 0.127 & 1 & -0.45 & 3 \\ \text { Connor Johnson } & \$ 75,500 & 4 & 3.45 & -1.20 & 25 & 0.797 & 2 & 0.682 & 2 \\ \text { Walter House } & \$ 90,000 & 4 & 3.40 & -1.32 & 10 & -1.21 & 2 & 0.682 & 3\end{array}$

$\begin{array}{ll}\text { Key } & \\ \text { Load } & \text { Teaching load (3-5) classes per academic year } \\ \text { Eval } & \text { Teaching evaluations based on student opinions of instructor } \\ \text { zEval } & \text { Standard score (normalized) for teaching evaluations of instructor } \\ \text { Cl Sz } & \text { Class size } \\ \text { zC S } & \text { Standard score (normalized) for class size } \\ \text { Grad } & \text { Graduate class } \\ \text { zGrad } & \text { Standard score (normalized) for graduate class } \\ \text { UG } & \text { Undergraduate class }\end{array}$


Table 3C

Service Productivity

Name
Henry McCarthy
George Guthridge
Brenda Dennison
Morgan Lowe
Jerry Jensen
Steven Benson
Samir Hamdan
Sam Chrisman
Loren Reiss
Patrick Kendrick
George Kessler
Loretta Matthews
Ben Jamieson
Terry Radford
Andy Keith
Perry Dickson
Peter Martinez
Richard Demming
Connor Johnson
Walter House

$\underline{\text { Key }}$

Uni

zUni

Sch

zSch

Dept

zDept

Pro

zPro

$\begin{array}{lcccccccc}\text { Salary } & \text { Uni } & \text { zUni } & \text { Sch } & \text { zSch } & \text { Dept } & \text { zDept } & \text { Pro } & \text { zPro } \\ & & & & & & & & \\ \$ 72,000 & 1 & 0.667 & 2 & 0.488 & 2 & 0.385 & 1 & 0.667 \\ \$ 68,000 & 1 & 0.667 & 2 & 0.488 & 1 & -1.54 & 0 & -1 \\ \$ 79,000 & 0 & -1 & 2 & 0.488 & 2 & 0.385 & 1 & 0.667 \\ \$ 82,500 & 0 & -1 & 2 & 0.488 & 1 & -1.54 & 2 & 2.333 \\ \$ 78,500 & 2 & 2.333 & 2 & 0.488 & 2 & 0.385 & 0 & -1 \\ \$ 72,500 & 1 & 0.667 & 1 & -1.95 & 2 & 0.385 & 1 & 0.667 \\ \$ 80,000 & 1 & 0.667 & 2 & 0.488 & 2 & 0.385 & 0 & -1 \\ \$ 81,000 & 0 & -1 & 2 & 0.488 & 2 & 0.385 & 0 & -1 \\ \$ 62,500 & 0 & -1 & 2 & 0.488 & 2 & 0.385 & 0 & -1 \\ \$ 86,000 & 1 & 0.667 & 2 & 0.488 & 2 & 0.385 & 0 & -1 \\ \$ 65,500 & 1 & 0.667 & 1 & -1.95 & 2 & 0.385 & 1 & 0.667 \\ \$ 74,000 & 1 & 0.667 & 2 & 0.488 & 3 & 2.308 & 1 & 0.667 \\ \$ 60,000 & 0 & -1 & 2 & 0.488 & 2 & 0.385 & 1 & 0.667 \\ \$ 79,500 & 0 & -1 & 1 & -1.95 & 2 & 0.385 & 0 & -1 \\ \$ 82,000 & 0 & -1 & 2 & 0.488 & 1 & -1.54 & 1 & 0.667 \\ \$ 76,000 & 1 & 0.667 & 1 & -1.95 & 2 & 0.385 & 1 & 0.667 \\ \$ 61,000 & 1 & 0.667 & 2 & 0.488 & 1 & -1.54 & 1 & 0.667 \\ \$ 65,000 & 1 & 0.667 & 2 & 0.488 & 1 & -1.54 & 1 & 0.667 \\ \$ 75,500 & 0 & -1 & 2 & 0.488 & 2 & 0.385 & 0 & -1 \\ \$ 90,000 & 0 & -1 & 2 & 0.488 & 2 & 0.385 & 0 & -1\end{array}$

University service

Standard score (normalized) for university service

School/College service

Standard score (normalized) for school/college service Departmental service

Standard score (normalized) for departmental service

Professional service

Standard score (normalized) for professional service 
Overall z-score rank ordering of merit recipients

\section{Table 3D}

Name

Henry McCarthy

George Guthridge

Brenda Dennison

Morgan Lowe

Jerry Jensen

Steven Benson

Samir Hamdan

Sam Chrisman

Loren Reiss

Patrick Kendrick

George Kessler

Loretta Matthews

Ben Jamieson

Terry Radford

Andy Keith

Perry Dickson

Peter Martinez

Richard Demming

Connor Johnson

Walter House

$*_{\mathrm{o}} / \mathrm{a}=$ overall z-score
Salary

$\$ 72,000$

$\$ 68,000$

$\$ 79,000$

$\$ 82,500$

$\$ 78,500$

$\$ 72,500$

$\$ 80,000$

$\$ 81,000$

$\$ 62,500$

$\$ 86,000$

$\$ 65,500$

$\$ 74,000$

$\$ 60,000$

$\$ 79,500$

$\$ 82,000$

$\$ 76,000$

$\$ 61,000$

$\$ 65,000$

$\$ 75,500$

$\$ 90,000$
* o/a z-score

0.93

0.61

0.34

0.32

0.28

0.23

0.19

0.18

0.16

0.14

0.09

0.00

$-0.10$

$-0.29$

$-0.38$

$-0.42$

$-0.43$

$-0.56$

$-0.60$

$-0.81$ 
Merit disbursement by percentage or as a fixed sum

\begin{tabular}{|c|c|c|c|c|c|c|c|}
\hline Name & Salary & $\begin{array}{c}\text { merit } \\
\text { by \%age } \\
4 \% \text { diff. }\end{array}$ & $\begin{array}{c}\text { Table } 4 \\
\text { merit as } \\
\text { \%age of } \\
\text { salary }\end{array}$ & $\begin{array}{c}\text { merit } \\
\text { as } \\
\text { fixed sum }\end{array}$ & $\begin{array}{c}\text { fixed sum } \\
\text { as \% of } \\
\text { merit \$ }\end{array}$ & $\begin{array}{c}\text { difference } \\
\text { between } \\
\% \text { vs fixed }\end{array}$ & $\begin{array}{c}\text { fixed sum } \\
\text { m\$ as \% } \\
\text { salary }\end{array}$ \\
\hline Henry McCarthy & $\$ 72,000$ & $9.37 \%$ & $\$ 6,744$ & $\$ 6,654$ & $8.93 \%$ & $\$ 90$ & $9.24 \%$ \\
\hline George Guthridge & $\$ 68,000$ & $9.37 \%$ & $\$ 6,369$ & $\$ 6,654$ & $8.93 \%$ & $(\$ 285)$ & $9.79 \%$ \\
\hline Brenda Dennison & $\$ 79,000$ & $9.37 \%$ & $\$ 7,399$ & $\$ 6,654$ & $8.93 \%$ & $\$ 745$ & $8.42 \%$ \\
\hline Morgan Lowe & $\$ 82,500$ & $9.37 \%$ & $\$ 7,727$ & $\$ 6,654$ & $8.93 \%$ & $\$ 1,073$ & $8.07 \%$ \\
\hline Jerry Jensen & $\$ 78,500$ & $9.37 \%$ & $\$ 7,352$ & $\$ 6,654$ & $8.93 \%$ & $\$ 698$ & $8.48 \%$ \\
\hline Steven Benson & $\$ 72,500$ & $9.37 \%$ & $\$ 6,790$ & $\$ 6,654$ & $8.93 \%$ & $\$ 136$ & $9.18 \%$ \\
\hline Samir Hamdan & $\$ 80,000$ & $5.37 \%$ & $\$ 4,293$ & $\$ 3,992$ & $5.36 \%$ & $\$ 300$ & $4.99 \%$ \\
\hline Sam Chrisman & $\$ 81,000$ & $5.37 \%$ & $\$ 4,346$ & $\$ 3,992$ & $5.36 \%$ & $\$ 354$ & $4.93 \%$ \\
\hline Loren Reiss & $\$ 62,500$ & $5.37 \%$ & $\$ 3,354$ & $\$ 3,992$ & $5.36 \%$ & $(\$ 639)$ & $6.39 \%$ \\
\hline Patrick Kendrick & $\$ 86,000$ & $5.37 \%$ & $\$ 4,615$ & $\$ 3,992$ & $5.36 \%$ & $\$ 622$ & $4.64 \%$ \\
\hline George Kessler & $\$ 65,500$ & $5.37 \%$ & $\$ 3,515$ & $\$ 3,992$ & $5.36 \%$ & $(\$ 478)$ & $6.10 \%$ \\
\hline Loretta Matthews & $\$ 74,000$ & $5.37 \%$ & $\$ 3,971$ & $\$ 3,992$ & $5.36 \%$ & $(\$ 22)$ & $5.40 \%$ \\
\hline Ben Jamieson & $\$ 60,000$ & $1.37 \%$ & $\$ 820$ & $\$ 1,331$ & $1.79 \%$ & $(\$ 511)$ & $2.22 \%$ \\
\hline Terry Radford & $\$ 79,500$ & $1.37 \%$ & $\$ 1,087$ & $\$ 1,331$ & $1.79 \%$ & $(\$ 244)$ & $1.67 \%$ \\
\hline Andy Keith & $\$ 82,000$ & $1.37 \%$ & $\$ 1,121$ & $\$ 1,331$ & $1.79 \%$ & $(\$ 210)$ & $1.62 \%$ \\
\hline Perry Dickson & $\$ 76,000$ & $1.37 \%$ & $\$ 1,039$ & $\$ 1,331$ & $1.79 \%$ & $(\$ 292)$ & $1.75 \%$ \\
\hline Peter Martinez & $\$ 61,000$ & $1.37 \%$ & $\$ 834$ & $\$ 1,331$ & $1.79 \%$ & $(\$ 497)$ & $2.18 \%$ \\
\hline Richard Demming & $\$ 65,000$ & $1.37 \%$ & $\$ 889$ & $\$ 1,331$ & $1.79 \%$ & $(\$ 442)$ & $2.05 \%$ \\
\hline Connor Johnson & $\$ 75,500$ & $1.37 \%$ & $\$ 1,032$ & $\$ 1,331$ & $1.79 \%$ & $(\$ 299)$ & $1.76 \%$ \\
\hline Walter House & $\$ 90,000$ & $1.37 \%$ & $\$ 1,230$ & $\$ 1,331$ & $1.79 \%$ & $(\$ 101)$ & $1.48 \%$ \\
\hline total payroll & $\$ 1,490,500$ & & & & & & \\
\hline $5 \%$ payroll /merit budget & $\$ 74,525$ & & $\$ 74,526$ & $\$ 74,525$ & $100 \%$ & & \\
\hline
\end{tabular}

Recipients of merit sorted by overall z-scores obtained from tables 3A, 3B, 3C, 3D

Table is categorized by $4 \%$ differentials 